\title{
BIOFEEDBACK AND STUTTERING
}

DR. E. GORDON (мввCH. BSC. HONS)

Baragwanath Hospital Johannesburg

DR. A. GORDON, (мввсн.)

L. GORDON, B.A. (SP \& H TH) WITWATERSRAND

M. SHAPIRO, B.A. (SP \& H TH) WTTWATERSRAND

M. MENTIS, B.A. (SP \& H TH) WITWATERSRAND

M. SUCHET, BSC (HONS.) WTTWATERSRAND

\section{SUMMARY}

Electromyographic biofeedback was used to reduce tension and enhance control of the speech associated muscles, resulting in a reduction of the frequency of stuttering. Five sessions were conducted over a course of three weeks. A mild, moderate and severe stutterer were assessed. A decrease in stuttering frequency was seen in each subject from pre to post biofeedback sessions on both a descriptive and an inferential level.

\section{OPSOMMING}

Elektromiografiese bioterugvoering is gebruik om spanning te verminder en kontrole van die spraakspiere te bevorder. Drie proefpersone met verskillende grade van hakkelsimptome is geëvalueer. ' $n$ Vermindering van hakkelfrekwensie is in elke proefpersoon, van pre- tot post-bioterugvoeringsessies op twee verskillende vlakke waargeneem.

Biofeedback therapy is the technique of monitoring, feeding back and thereby learning control of involuntary physiological responses, or learning more sophisticated control over voluntary responses. A simple diagramatic representation of a biofeedback loop is delineated below.

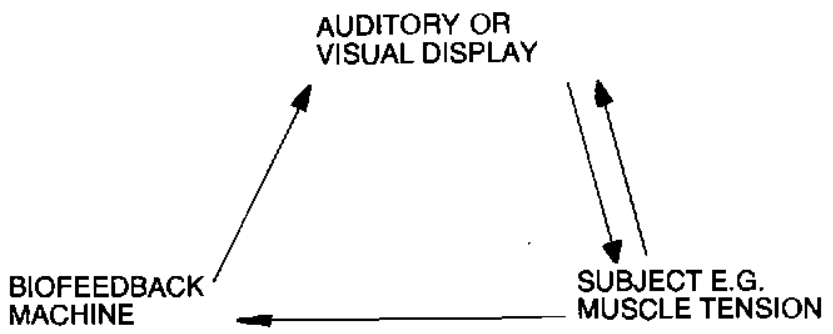

Any physiological parameter e.g. the tone of the speech related muscles, are monitored via the biofeedback machine. The response is amplified and converted into a visual and/or audial display, which is easily interpreted by the subject. The subject gains an impression, from the display, of e.g. the tone of speech muscles. It is via this feedback that the subject may learn to re-educate these muscles. The new physiological response is learnt through operant conditioning. 
The reward is the sense of success which is able to be interpreted via the biofeedback machine. ${ }^{6,7}$

Biofeedback therapy has a wide range of applications including EEG, cardiovascular, neuromuscular and gastro-intestinal behaviour modifications.

Stuttering is considered by numerous researchers to be accompanied by spasm of the laryngeal muscles (Van Riper, ${ }^{12}$ ). A pilot study by Richmond et al (1975) reported that auditory biofeedback of laryngeal muscle tension reduced stuttering in a single subject. The study demonstrated that there was an intimate relationship between laryngeal tension and stuttering.

Electromyographic investigations by Freeman and Ushijima (1975) lend support to the hypothesis that the laryngeal behaviour associated with certain of the stutterings, is related to simultaneous contraction of antagonistic laryngeal muscles.

Since speech is but part of the total mechanism of communication it is evident that the central co-ordination of speech movements will be involved with a variety of additional muscular activities associated with expression (e.g. facial, head, arm, hand movements) and that these may consequently be affected by factors causing disharmony in speech itself (Dewar et $\mathrm{al}^{3}$ ).

Using electromyographic recorders on the masseter muscles it has been demonstrated that there is an increase in muscle tension in stutterers as opposed to non-stutterers (Williams, ${ }^{11}$; Shrum, ${ }^{9,}{ }^{10}$ ).

Shrum ${ }^{10}$ measured surface electrical activity of facial neck and chest muscles in stutterers. He observed a relationship between increases in electromyographic signal amplitude prior to speech and stuttering. Stuttering was apparently preceded by an early and sustained rise in signal amplitude in almost all muscles studied.

Elimination of covert pre-utterance activity was achieved by employing an audible analog of electromyographic activity to train stutterers to begin speaking with nearly resting levels of muscle action potentials. If feedback is progressively reduced in learning situations, control may become a "proprioceptive" skill permitting unobtrusive and perhaps automatic maintenance of fluency (Hefferline, ${ }^{5}$ ).

The technical aspects of muscular action and of electromyography in speech research have been comprehensively dealt with in the literature (Fromkin and Ladefoged, ${ }^{4}$ Ohrian et al., ${ }^{8}$ Buchthal $^{2}$ ).

\section{METHODOLOGY}

AIM

To demonstrate that using electromyographic (EMG) biofeedback, subjects can control the muscles related to speech and reduce the frequency of stuttering. 


\section{SUBJECTS}

The subjects were volunteers in response to an advert in the university newspaper. The subjects were adults ranging in age from 27 to 37 years and had a long history of stuttering with onset in early childhood. All subjects had previously received therapy at various stages in their lives. No subject had a prior knowledge of biofeedback. There was one female and two male subjects.

Subject A's stuttering pattern was characterized by infrequent cessation of vocal activity on the initial sound of the word. He was classified both by frequency and severity as a mild stutterer.

Subject B's stuttering pattern was characterized by sound and word repetitions and prolongations with a rise in pitch. She was classified as a moderate stutterer in both frequency and severity.

Subject C's stuttering pattern was predominantly characterized by deep inhalation associated with facial contortion, before initiating words. Other stuttering symptoms were facial tremor, grimacing, flaring of nostrils and peripheral tension. Subject $C$ was classified as a severe stutterer in terms of frequency and severity.

\section{MATERIALS AND METHOD}

Two model Atlas 251A six function physiological data monitoring and feedback systems were used. For the purpose of this study the EMG biofeedback was utilized. Signals from two electrodes were collected, averaged and then converted into two types of feedback, a visual meter reading (an amp. meter) and a variable frequency audio tone. A reduction in the subject's tension produced lower meter readings and lower auditory frequencies. Auditory feedback was received by the subject through an earphone.

The muscle groups selected were:

(a) Peri-oral muscle groups.

On these mimetic muscles the electrodes were placed onto the angle of the mouth.

(b) The laryngeal muscle group.

Two surface EMG electrodes were attached one on either side of the neck midline, approximately one $\mathrm{cm}$ superior to the thyroid cartilage, hereby assessing the laryngeal muscle group.

A ground electrode was attached five $\mathrm{cm}$ below the elbow on the ulna bone.

All three subjects read the same passage from a child's reading book. They were then asked to speak spontaneously. It is customary when estimating the frequency of stuttering moments to use the above two methods (Aron ${ }^{1}$ ). In addition the subjects described Thematic Apperception Tests (TAT).

This was included in an attempt to measure the effect of biofeedback on stuttering while the subject was pre-occupied with creative thinking. All speech was tape recorded so that it could be transcribed and the 
moments marked and studied by four testers. Ratings of all items were based on frequency and not severity of stuttering.

The counting of the stuttering moments constituted the basic measurements of the disorder. This was in accordance with Sherman et al (1958), who compared three measures of stuttering severity, namely reading time, frequency moments of stuttering and scale values from listeners ratings. Interrelationships were found to be statistically significant and the strength of the relationship was highest between the frequency counts and the rated severity.

Five sessions were conducted over a course of three weeks with equal intervals inbetween. The same clinical therapy rooms were utilized throughout. Each biofeedback session consisted of one hour, subdivided in the following way:

(i) A baseline stuttering frequency was assessed at the start and end of each session.

The biofeedback equipment was disconnected during the baseline assessments in order to minimize the effect of distraction.

(ii) In the initial 10 minutes of the first session the subject received a succinct explanation of the anatomy and physiology of the speech mechanism. The potential role of biofeedback in these muscle groups associated with stuttering was explained in an appropriate fashion.

(iii) The aim of the first half of the biofeedback session was for the subject to master and reinforce the relaxation of the specific muscle group selected.

(iv) The second half of the biofeedback session was to extend this relaxation training to the speaking situation.

Two therapists conducted each training session, alternating on a rotatory basis to minimize the effect of subject familiarity.

\section{RESULTS}

Figures 1, 2 and 3 delineate the results obtained.

The mean combined stuttering frequencies of reading, TAT, and free speech, before and after biofeedback training, are seen in figure one. On a descriptive level a reduced stuttering frequency can be seen for each subject, from pre to post biofeedback training. Subject $A$ showed a decrease of $38,5 \%$, subject $\mathrm{B} \cdot 35,6 \%$, and subject C $26 ; 2 \%$. The mean decrease in stuttering frequency for the total sample'was $33,4 \%$. On an inferential level these decreases are statistically significant.

In both the one way and two way analysis of variance a significant difference was found between pre and post biofeedback. This was significant at the $6,1 \%$ level. No significant difference was found at the $10 \%$ level between the different methods of analysis, nor between the sessions.

Figure 2 illustrates the cumulative mean results of each subject's stuttering frequency, measured at, the beginning and end of each 


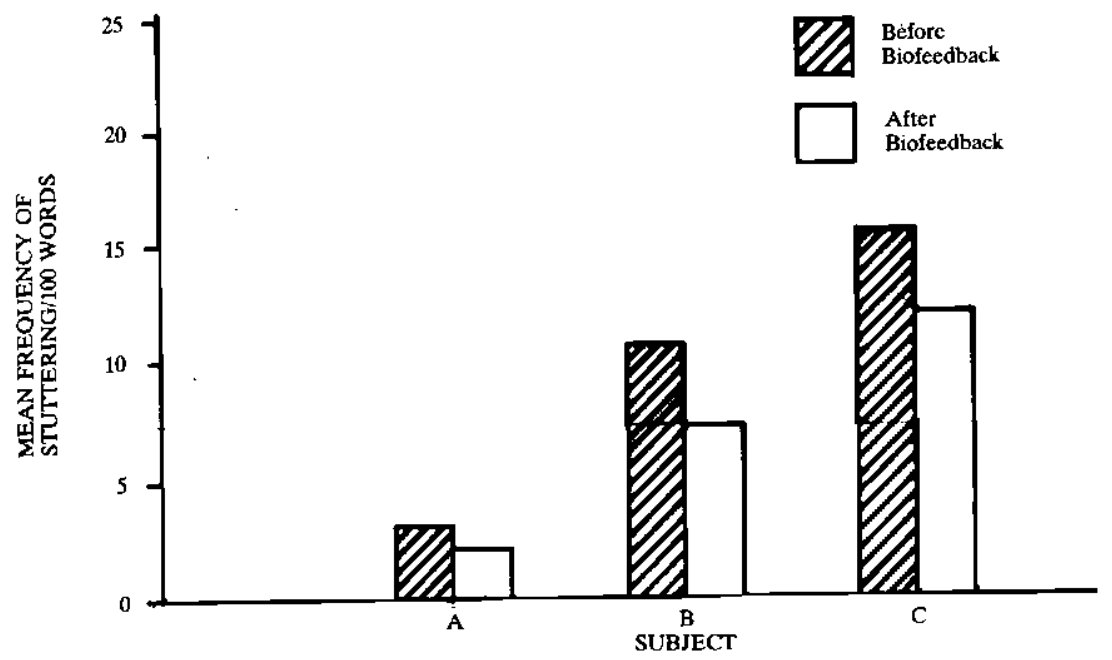

Figure 1: The mean combined reading, TAT, and free speech stuttering frequencies before and after biofeedback.

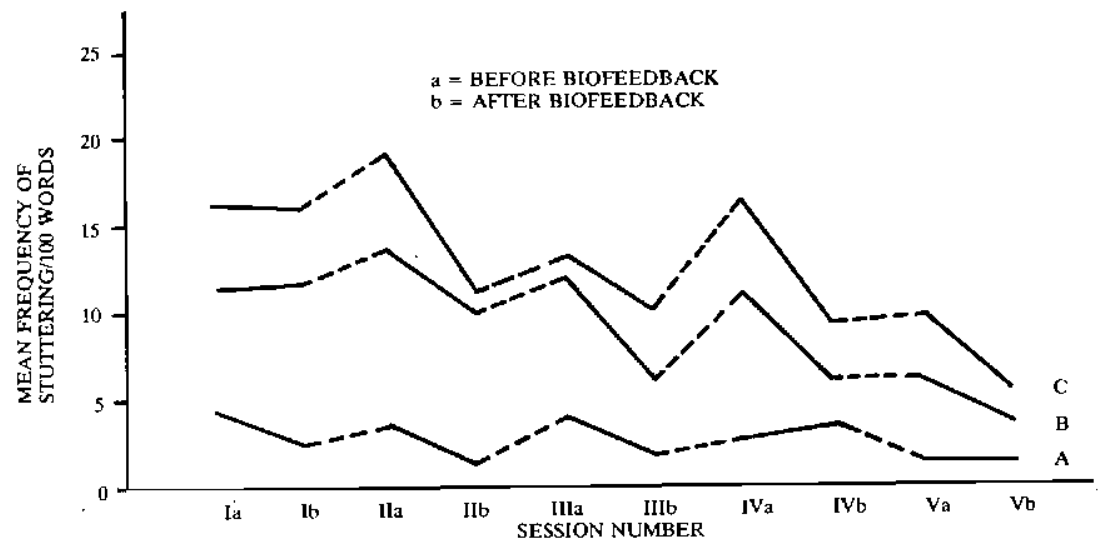

Figure 2: The cumulative mean frequency of stuttering/100 words, measured at the beginning and end of each session, over five sessions.

session. On a descriptive level, the stuttering frequency carry over from the end of one session to the beginning of the next is intermittently reduced. However, on an inferential level, this carry over is not statistically significant.

Figure 3 illustrates the differences in the three methods of analysis of stuttering frequency (Free Speech, TAT and Reading). In all cases reading showed a marked decrease in relation to TAT and free speech. This is especially noticeable in subjects $\mathrm{B}$ and $\mathrm{C}$ in which decreases were $73 \%$ and $78 \%$ respectively. 


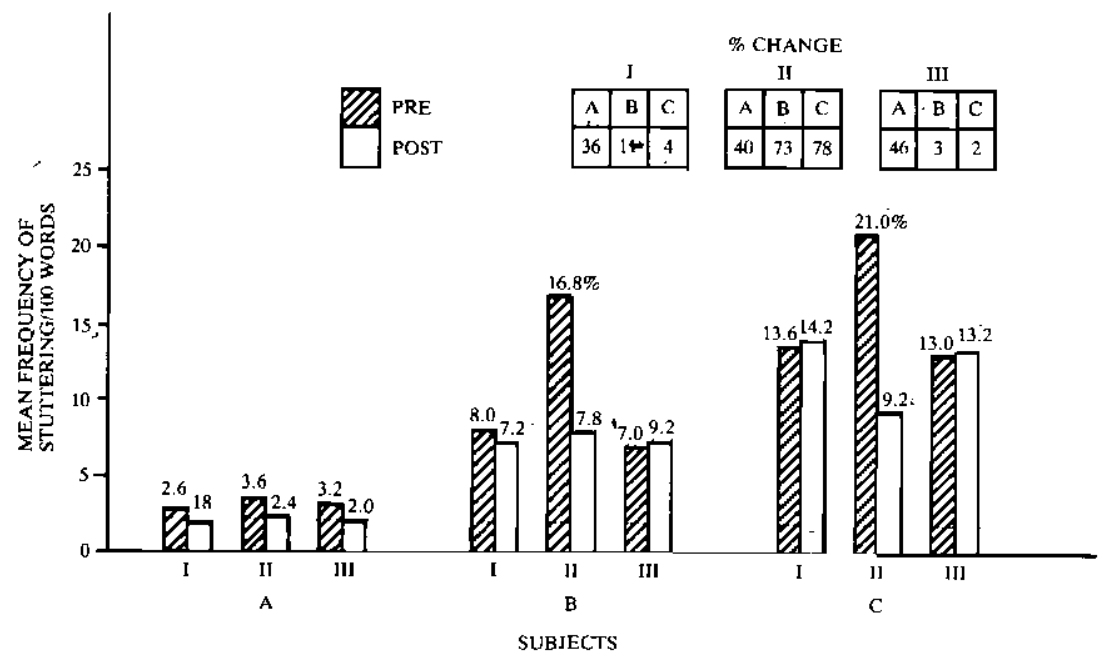

\footnotetext{
(i) Thematic apperception test (iat)

(ii) Reading

(iii) Free speech
}

(Figure 3 demonstrates the numerical and percentage change in mean frequcncy of stuttering/100 words from PRE BIOFEEDBACK PROGRAMME to POST BIOFEED. BACK PROGRAMME;)

Figure 3: A comparison of the three different methods of analysing stuttering frequency (free speech, TAT, and reading).

\section{DISCUSSION}

Pertinent to this report as a pilot study are additional subjective (patient and therapist) perceptions. Most evident was subject $C$, in whom quantitative analysis yielded the least decrease in stuttering but in whom the stuttering pattern was markedly changed. The subject spoke in a more controlled manner and demonstrated a reduction of head shaking, deep inhalation and facial contortion. This would concur with the findings of Dewar et $\mathrm{al}^{3}$. He noted that abnormal activity of the orbicularis oculi muscles concomitàn with stammering was abolished at the same time as the speech disfluency, by larynx triggered auditory feedback masking.

Subject A, although demonstrating mild symptomatology, stated that he had benefitted from the programme and that his family had noticed an improvement in his speech.

Subject B, felt that he had benefitted in that the relationship between tension and stuttering had been highlighted for him. He felt he was able to gain control of both general and focal tension areas. A positive influence was the encouragement he had received from his family, who expressed having noticed improvement in his speech.

All three subjects strongly felt that maximum benefit would be derived from a more intensive programme. Stuttering has been reported to be 
under stimulus control. When trying to alter a well learned habit pattern numerous opportunities may be required in the re-education, reinforcement and internalization of the new task.

Regardless of severity, all 3 subjects benefitted from biofeedback training.

Much criticism has been levelled at current trends in stuttering therapy and it has been expressed that the success achieved in some instances is often short lived and may be attributed to distraction.

Dewar et $\mathrm{al}^{3}$ used an apparatus providing an auditory feedback masking noise triggered by means of a throat microphone switch. Evaluation tests of this device made on 53 stammerers demonstrated its effectiveness in reducing stammering and abolishing gross concomitant movements. An attempt was made to eliminate the influence of distraction and no biofeedback machinery was used during the evaluation of the pre or post experimental baselines.

It was felt that the age of the subjects was a limitation of the study. The subjects had been exposed to many forms of stuttering therapy which have determined their present attitudes with regard to the success of stuttering treatment. An intense training.period with a group of adolescent stutterers is being investigated by the authors. With conservative modalities of therapy adolescents have proved to be difficult to work with and often resistant to becoming involved in a therapeutic relationship. The use of sophisticated machinery may stimulate an interest and motivation in the adolescent stutterer.

\section{CONCLUSIONS}

1. Biofeedback was found to significantly decrease stuttering within sessions in all of the subjects tested.

2. On a descriptive level an intermittent carry-over of reduced stuttering between sessions was evident. On an inferential level however this trend was not statistically significant.

3. A mild, moderate and severe stutterer achieved significant reductions in stuttering frequency with biofeedback training.

4. Biofeedback re-education may have a place in the management of stuttering.

\section{ACKNOWLEDGEMENTS}

The authors wish to express their thanks to Prof. M. L. Aron, Head, Department of Speech Pathology and Audiology, University of the Witwatersrand, for granting permission for the subjects to be used in this study.

\section{REFERENCES}

1. Aron M. L. (1967) The Relationships Between Measurements of Stuttering Behaviour. Journal of the South African Logopedic Society, Vol. 14, No. 1. 
2. Buchthal, F. (1960) The general concept of the motor unit. Res. Publ. Ass. Nerv. Ment. Dis. 38, 1.

3. Dewar, A., Dewar, A. D., Anthony, J. F. K. (1976) The Effect of Auditory Feedback Masking on Concomitant Movements of stammering. British Journal of Disorders of Communication.

4. Fromkin, Victoria and Ladefoged, P. (1966) Electromyography in Speech Research. Phonetica, 15, 219.

5. Hefferline, R. (1958) The Role of Proprioception in the Control of Behaviour. Trans. N:Y. Acad. Sci., 20, 739.

6. Kinsman, R. A. G. Staudenmayer, H. (1978) Baseline Levels in Muscle Relaxation Training. Biofeedback and Self-Regulation. 3, 87-194.

7. Lanyon, R. I. et al (1976) Modification of Stuttering through EMG Biofeedback, A preliminary Study. Behaviour Therapy 7 , 96-103 Academic Press New York.

8. Ohrian, S. et al (1965) Electromyographic Studies of Facial Muscles During Speech. STL-QPSR-3/1965. Speech Transmission Laboratory, Royal Institute of Technology, Stockhölm.

9. Shrum, W. F. (1967-1968). The Study of the Study of the Speaking Behaviour of Stutterers and Non-Stutterers by Means of Multichannel Electromygraphy. Dissertation Abstracts A. Cushing-Malloy, Inc., Ann Arbor Michigan, U.S.A.

10. Shrum, W. (1969) A Study of Speaking Behaviour of Stutterers and Non-Stutterers By Means of Multichannel Electromyography. Doctoral dissertation, Univ. of Iowa.

11. Williams, D. E. (1955) Masseter Muscle Action Potentials in Stuttered and Non-Stuttered Speech. Journal of Speech and Hearing Disorders 20, 242-261.

12. Van Riper, C. (1971) The Nature of Stuttering. Englewood Cliffs. N.J. Prentice Hall. 


\section{Does the Child Hear? In many cases, only the ABR can tell.}

Infants, young children, retarded individuals, and other non-communicative patients can't accurately describe their hearing. The auditory brainstem response $(\mathrm{ABR})$ is a iensitive tool for objectively identifying and diagnosing hearing disorders in such persons It provides exact information about the functional status of the cochlea and brainstem pathways that cannot be obtained by other test.s, behavioral or physiologic. lt is a reliable method for measuring hearing threshold. Further, the technique distinguishes recruiting from non-recruiting losses, and retrochochlear from peripheral disorders.

\section{Pediatric Evaluation}

The $\mathrm{ABR}$ is especially valuable in screening high-risk infants, testing infunts with congenital malformations, and in

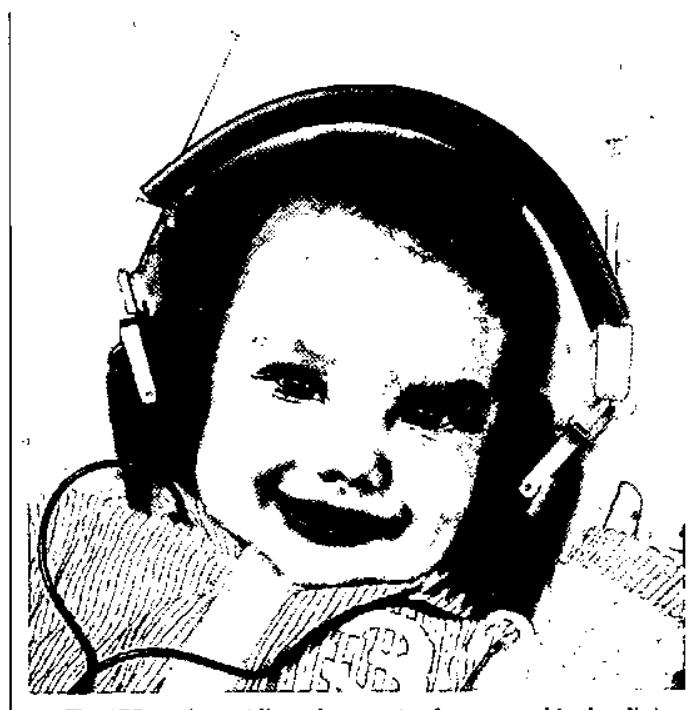

The ABR can be rapidly and conveniently measured in the clinic or at the bedside. Click stimuli deltvered through earphones elicit the ABR, which is measured from electrodes placed on the patient's head.

assessing other hard-to-test children. Such early determinations allow proper manágement, ensuring normal linguistic skill development.

\section{Acoustic Tumor Detection}

With proper interpretation, the $A B R$ is an efficient test in the early diagnosis of acoustic tumors.

In short, the ABR technique can serve as a significant and valuable tool for the otologist and audiologist.

\section{A complete system} from Nicolet, the established leader in ABR Instrumentation.

The Nicolet CA-10OO is a complete, clinically-proven system for recording etoked potentials. Its ease of operation and portability make it ideal for clinical use. Nicolet's 14 vears of leadership in evoked potential technology provide the CA-1000 user with an unequalled support system, including regional sales and service, on-site training, and workshops on recording techniques and diagnostic applications.

please phone or write for further details or to arrange for $a$ demonstration.

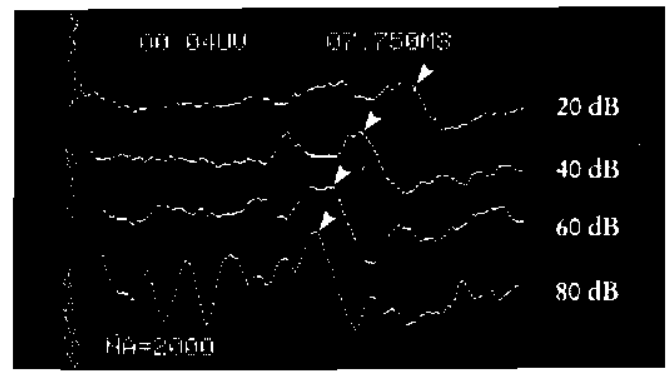

A typical series of ABRs measured at varying click intensities. Each ABR is the summation of responses from 2000 click stimuli. The individual waves represent the sound-induced neural activity as in ascends the auditory pathway. The weakest click that produces a waye $V$ response establishes the hearing threshold.

Galambon R, Hecur K: Clinleal applications of the zuditory brainstern response. Orolaryngol. Clin. North Am. 11:709-722, 1978.

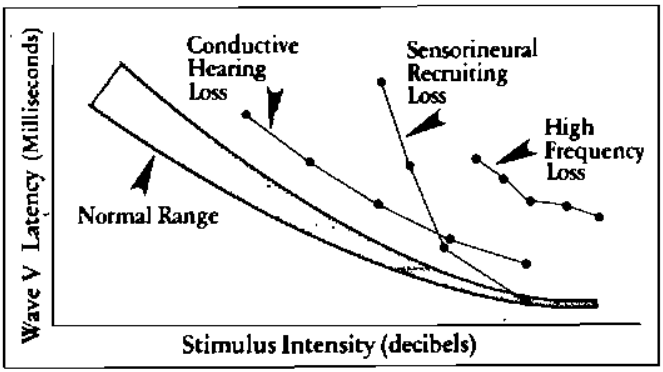

Curves of waye $Y$ latencies as a function of intensity. Curves obtained from hearing-impaired patients difier from the normal curve. These difierences determine both magnitude and type of hearing loss.

Picion $\mathrm{T}$ w, et. al: Evoted Polential Audiometry. J. Clemis J D, MrGee T: Brain sicm electric response audiometry in the dititerential djagnosis of aronestic tumors. Laryngoscope, LXXX1X: 31-42., 1979.

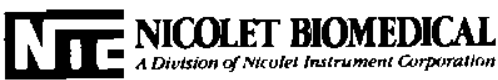

P.O. Box 6270 Johannesburg. South Afrlca 2000.

6th Floor, Spescom House, comer Ploneer and Central Roads

Fordsburg, Johannesburg 2092. Telex: 8-6273. Telephone: (0 11) 834-7551

Die Suid-Afrikaanse Tydskrif vir Kommunikasieafwykings, Vol. 28, 1981 